08.1

\title{
Белые нанолюминофоры на основе модифицированных ионами европия монодисперсных углеродных наноточек
}

\author{
(ㅇ Д.А. Курдюков ${ }^{1}$, Д.А. Еуров ${ }^{1}$, М.К. Рабчинский ${ }^{1}$, Д.А. Кириленко ${ }^{1}$, М.М. Бржезинская ${ }^{2}$, С.Д. Савельев ${ }^{1}$, \\ А.Н. Смирнов ${ }^{1}$, В.Г. Голубев ${ }^{1}$ \\ ${ }^{1}$ Физико-технический институт им. А.Ф. Иофффе РАН, Санкт-Петербург, Россия \\ ${ }^{2}$ Helmholtz-Zentrum Berlin für Materialien und Energie, Berlin, Germany \\ E-mail: edan@mail.ru
}

Поступило в Редакцию 23 декабря 2021 г.

В окончательной редакции 24 января 2022 г.

Принято к публикации 24 января 2022 г.

Темплатным методом синтезированы монодисперсные углеродные наноточки, модифицированные ионами европия, обладающие фотолюминесценцией во всей видимой области спектра. Химический состав и структура полученного белого нанолюминофора исследована рентгеноспектральными и микроскопическими методами.

Ключевые слова: углеродные наноточки, нанолюминофор, европий.

DOI: 10.21883/PJTF.2022.07.52289.19116

Люминофоры, состоящие из наноразмерных частиц (нанолюминофоры), вследствие квантово-размерных эффектов и функционализированной развитой поверхности обладают по сравнению с массивными люминофорами новыми свойствами, такими как слабое концентрационное тушение люминесценции, нелинейные оптические эффекты, перестраиваемый спектр излучения [1,2]. Нанолюминофоры перспективны для применения в оптоэлектронике в светодиодах белого цвета свечения и в биомедицине в качестве люминесцентных маркеров [1,2]. Нанолюминофорами являются, в частности, углеродные наноточки (carbon nanodots, CD), обладающие уникальными свойствами, такими как простота синтеза, яркая фотолюминесценция (ФЛ), фотостабильность, низкая токсичность, биосовместимость [3-5]. Как правило, ширина спектра ФЛ CD существенно меньше видимого спектрального диапазона [3-5]. Для создания белых нанолюминофоров зачастую используют смеси CD c нанолюминофорами другого состава, например содержащими ионы редкоземельных элементов, или смешивают несколько образцов CD разных цветов свечения $[4,6,7]$.

В одной из предыдущих публикаций [8] авторами настоящей работы было показано, что субмикронные композитные частицы, представляющие собой $\mathrm{CD}$, внедренные в матрицу мезопористого кремнезема $\left(\mathrm{mSiO}_{2}\right)$, обладают яркой широкополосной ФЛ и могут быть успешно использованы в качестве люминофора для светодиодов. Спектр УФ-светодиода с нанесенным на его поверхность слоем частиц $m \mathrm{SiO}_{2} / \mathrm{CD}$ по интенсивности и форме был близок к спектрам коммерческих светодиодов холодного белого света [8]. Целью нашего исследования была разработка подхода для получения белого нанолюминофора, представляющего собой монодисперсные CD (MCD) с более широким спектром ФЛ, включающим в себя весь видимый диапазон. Разработанный подход ос- нован на одновременной термодеструкции в мезопорах $m \mathrm{SiO}_{2}$ азотсодержащего органосилана и соли, состоящей из редкоземельного катиона $\left(\mathrm{Eu}^{3+}\right)$ и органического аниона, с последующим удалением темплата. Внедрение сильно электроположительного элемента вызвало изменение состава и электронной структуры наноточек, что в свою очередь приводило к модификации спектра ФЛ.

Используемые в качестве темплата для синтеза MCD:Eu монодисперсные сферические частицы $m \mathrm{SiO}_{2}$ диаметром $510 \pm 20 \mathrm{~nm}$ получены гидролизом тетраэтоксисилана в спирто-водно-аммиачной среде, содержащей поверхностно-активный структурообразующий агент [9]. Внутри частиц $m \mathrm{SiO}_{2}$ имеется система плотноупакованных монодисперсных цилиндрических пор диаметром $3.1 \pm 0.2 \mathrm{~nm}$. Объемная доля пор составляет $50 \mathrm{vol} . \%$ от объема $\mathrm{mSiO}_{2}$. Синтез $\mathrm{MCD}: \mathrm{Eu}$ проводился посредством термического разложения прекурсоров в порах $m \mathrm{SiO}_{2}$. Частицы кремнезема $(1 \mathrm{~g})$ однократно пропитывались спиртовым раствором прекурсоров - $0.2 \mathrm{~g}$ аминопропилтриэтоксисилана (APTES) и $0.05 \mathrm{~g}$ ацетата европия. После этого частицы высушивались при $50^{\circ} \mathrm{C}$ и отжигались на воздухе при $250^{\circ} \mathrm{C}$ в течение $5 \mathrm{~h}$. Монодисперсность мезопор и одинаковый размер частиц темплата $m \mathrm{SiO}_{2}$ [9] обусловливали одинаковые форму и низкий разброс по размерам $[10,11]$ синтезируемых наноточек, а следовательно, одинаковые физические и химические свойства. Ранее было показано, что квантовый выход $\mathrm{MCD}$, синтезированных в порах $m \mathrm{SiO}_{2}$, достигает 14\% [12]. Удаление материала темплата (аморфного $\mathrm{SiO}_{2}$ ) из композитных частиц $m \mathrm{SiO}_{2} / \mathrm{MCD}: \mathrm{Eu}$ осуществлялось травлением в растворе $\mathrm{HF}$.

Спектры ФЛ (рис. 1) люминофоров до и после удаления темплата измерялись на спектрометре Horiba Jobin Yvon T64000 при комнатной температуре. В качестве источника возбуждения использовался $\mathrm{He}-\mathrm{Cd}-л а-$ 


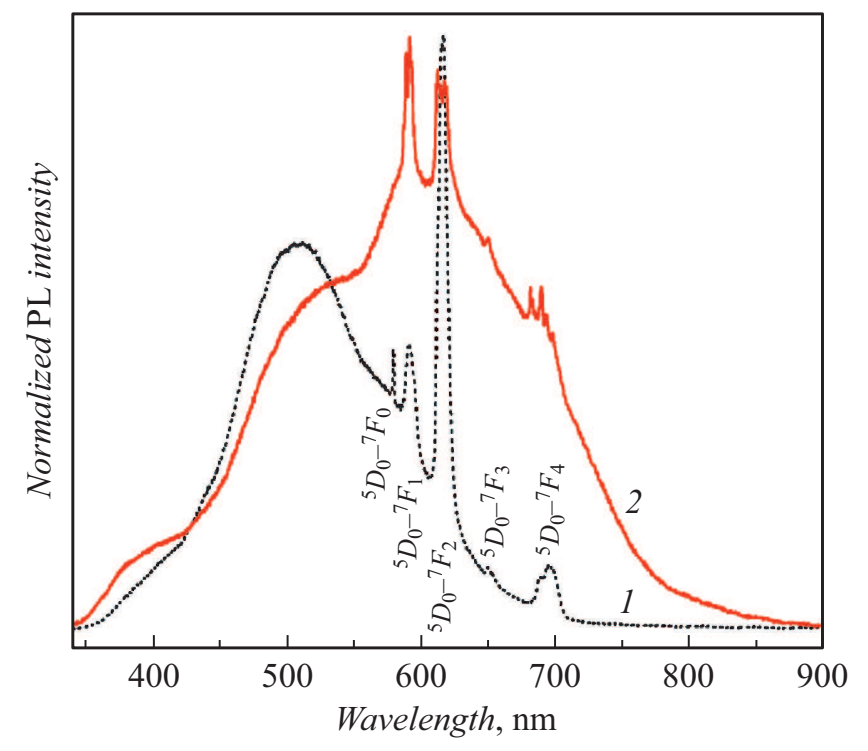

Рис. 1. Спектры ФЛ $\left(\lambda_{e x}=325 \mathrm{~nm}, T=300 \mathrm{~K}\right)$ субмикронных монодисперсных сферических композитных частиц $m \mathrm{SiO}_{2} / \mathrm{MCD}: \mathrm{Eu}(1)$ и наноточек $\mathrm{MCD}: \mathrm{Eu}$ после удаления материала темплата (2).

зер $\left(\lambda_{e x}=325 \mathrm{~nm}\right)$. Плотность лазерного излучения на поверхности люминофоров была $0.4-10 \mathrm{~kW} / \mathrm{cm}^{2}$. В спектрах ФЛ композитных частиц $m \mathrm{SiO}_{2} / \mathrm{MCD}: \mathrm{Eu}$ и наноточек MCD : Еu наблюдаются широкие структурированные полосы, обусловленные излучением углеродных наноточек. Отметим, что полоса в спектре $m \mathrm{SiO}_{2} / \mathrm{MCD}: \mathrm{Eu}$ (кривая 1 на рис. 1) совпадает со спектром ФЛ композитных частиц $m \mathrm{SiO}_{2} / \mathrm{CD}$, которые ранее наносились на поверхность УФ-светодиода [8]. В спектрах ФЛ на рис. 1 также проявляются узкие полосы, соответствующие внутрицентровым переходам в $\mathrm{Eu}^{3+}:{ }^{5} D_{0}-{ }^{7} F_{J}(J=0-4)$. Соотношение интенсивностей полос ФЛ ионов европия в спектрах материала до и после травления $\mathrm{mSiO}_{2}$ различается благодаря тому, что в спектр ФЛ композитных частиц вносит дополнительный вклад излучение ионов $\mathrm{Eu}^{3+}$, находящихся в матрице $a-\mathrm{SiO}_{2}$, которые удаляются вместе с материалом темплата в процессе травления. Ионы $\mathrm{Eu}^{3+}$ внедряются в кремнезем в результате реакции прекурсора с материалом матрицы. Различие спектров ФЛ CD (индивидуальных и диспергированных в матрице $m \mathrm{SiO}_{2}$ ) может быть обусловлено разным окружением [13] и концентрацией наноточек, a также возможным изменением состава MCD:Eu при травлении в НF.

Морфология нанолюминофора исследовалась на просвечивающем электронном микроскопе Jeol JEM-2100F. Обнаружено, что при высушивании нейтрального гидрозоля $\mathrm{MCD}: \mathrm{Eu}$ образуются сферические субмикронные агрегаты (рис. 2,a), что, как показано ранее [11], подтверждает монодисперсность и одинаковые форму и состав частиц (в гидрозоле каждая углеродная наноточка притягивает и отталкивает одинаковым образом). На картинах электронной микродифракции от агрегатов (рис. $2, b)$ присутствует кольцо, соответствующее межплоскостному расстоянию $0.35 \mathrm{~nm}$, при этом ширина кольца соответствует кристаллитам с характерным размером около $3 \mathrm{~nm}$ [14]. При высушивании разбавленных основных гидрозолей методом просвечивающей электронной микроскопии (ПЭМ) регистрируются индивидуальные MCD: Eu размером 3-4 nm (рис. 2,c).

Детальные данные о химическом составе и структуре MCD были получены методами рентгеновской фотоэлектронной спектроскопии (РФЭС) и рентгеновской спектроскопии поглощения (РСП) с использованием синхротронного излучения на высоковакуумной экспериментальной станции на канале „Российско-германская лаборатория BESSY-II“ (Берлин, Германия), подробно методика описана в работах $[11,15]$. На рис. $3, a$ представлены обзорные рентгеновские фотоэлектронные (РФЭ) спектры MCD:Eu (кривая 1) и MCD, синтезированных из APTES $[10,11]$ без добавления ацетата европия (кривая 2). В спектре $\mathrm{MCD}: \mathrm{Eu}$ наряду с остовными линиями С $1 s(284.7 \mathrm{eV}), \mathrm{N} 1 s(400.1 \mathrm{eV})$ и $\mathrm{O} 1 s(532.5 \mathrm{eV})$ появляются особенности, обусловленные наличием европия. В частности, возникают остовные линии $\mathrm{Eu} 4 p_{3 / 2}$ при $267.1 \mathrm{eV}$, дублет Еu $4 d$ с энергиями связи 143.0 и $136.9 \mathrm{eV}$, а также линия $\mathrm{Eu} 5 s$ вблизи $29.1 \mathrm{eV}$, которая накладывается на остовную линию O $2 s$ с близким значением энергии связи [16]. Результаты количественного анализа РФЭ-спектра демонстрируют, что концентрация введенного Еu составляет $\sim 1.2$ at.\%. В то же время концентрации $\mathrm{C}, \mathrm{N}$ и $\mathrm{O}$ составляют 73.6, 6.0 и 19.2 at.\% соответственно. Сравнение данных величин с соответствующими значениями для немодифицированных MCD (80.7, 10.2 и 9.1 at.\%) показывает, что процесс модификации наноточек ионами европия сопровождается существенным, более чем двукратным, ростом концентрации $\mathrm{O}$ и одновременным почти двукратным снижением концентрации N. По-видимому, в процессе синтеза наноточек фрагменты соединений или ионы $\mathrm{Eu}^{3+}$ локализуются вблизи дефектных областей углеродной матрицы $\mathrm{MCD}$, препятствуя образованию пиррольных и пиридиновых циклов.

Состав азот- и кислородсодержащих групп в наноточках определен по спектрам рентгеновского поглощения (РП) (рис. $3, b, c)$. Деконволюция остовных $\mathrm{N} 1 s$ и $\mathrm{C} 1 s$ РФЭ-спектров, также позволяющая выявить состав функциональных групп [17], не проводилась, так как форма спектральных линий искажена вследствие зарядки образцов во время измерения. На присутствие азотных гетероциклических соединений как в MCD:Eu, так и в MCD указывает наличие в спектрах $K$-края поглощения $\mathrm{N}$ (рис. $3, b$ ) высокоинтенсивных $\pi^{*}$-резонансов вблизи 398.9 и $399.8 \mathrm{eV}$. Данные спектральные особенности отвечают резонансным переходам остовных $1 s$-электронов на $\pi^{*}$-орбитали в атомах $\mathrm{N}$ в пиридиновых и пиррольных гетероциклах соответственно $[18,19]$. В обоих РП-спектрах также присутствует $\pi^{*}$-резонанс электронных переходов в третичных аминах 

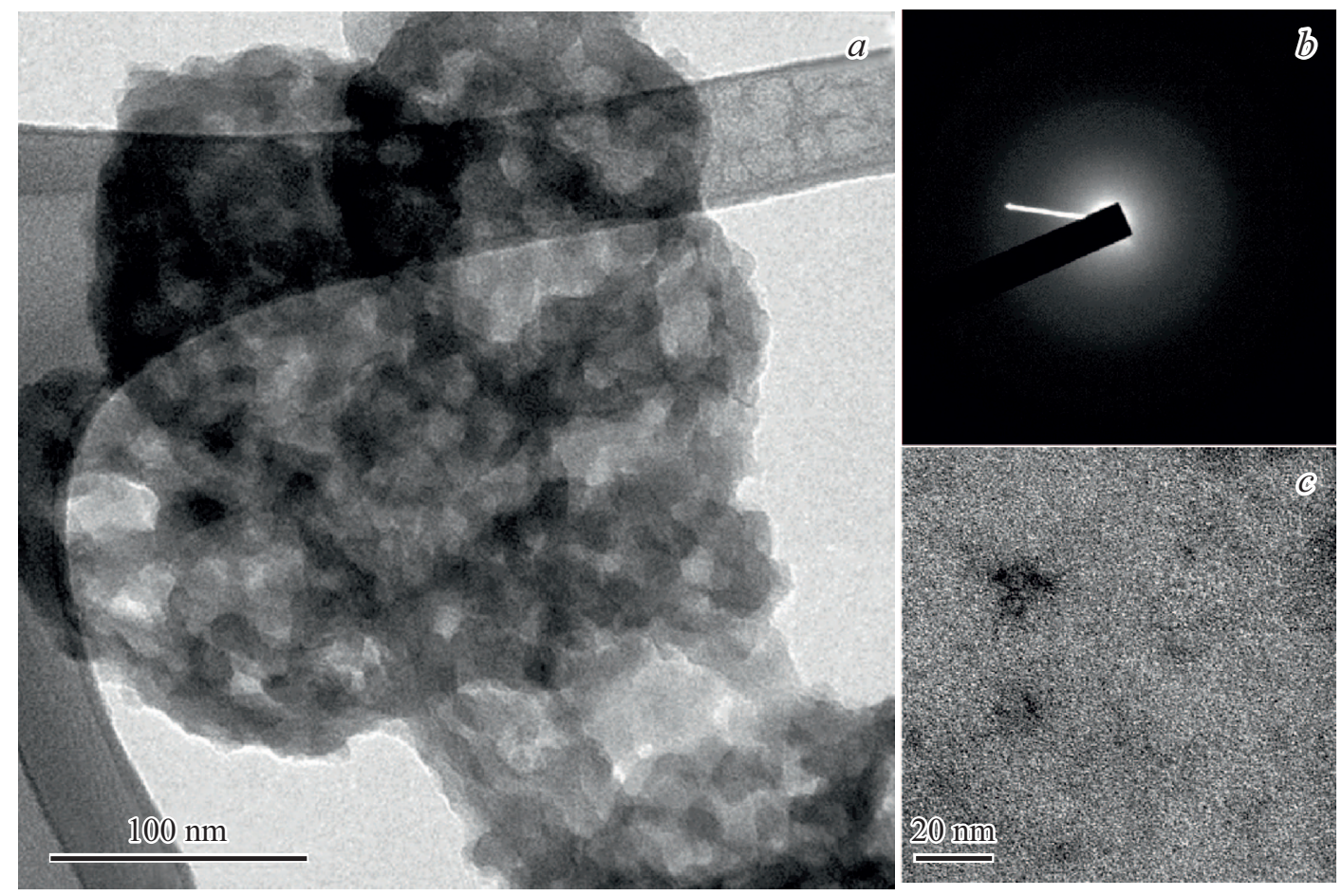

Pис. 2. ПЭМ-изображение $(a)$ и микродифракция $(b)$ агрегатов $\mathrm{MCD}: \mathrm{Eu} . c-$ ПЭМ-изображение индивидуальных $\mathrm{MCD}: \mathrm{Eu}$.
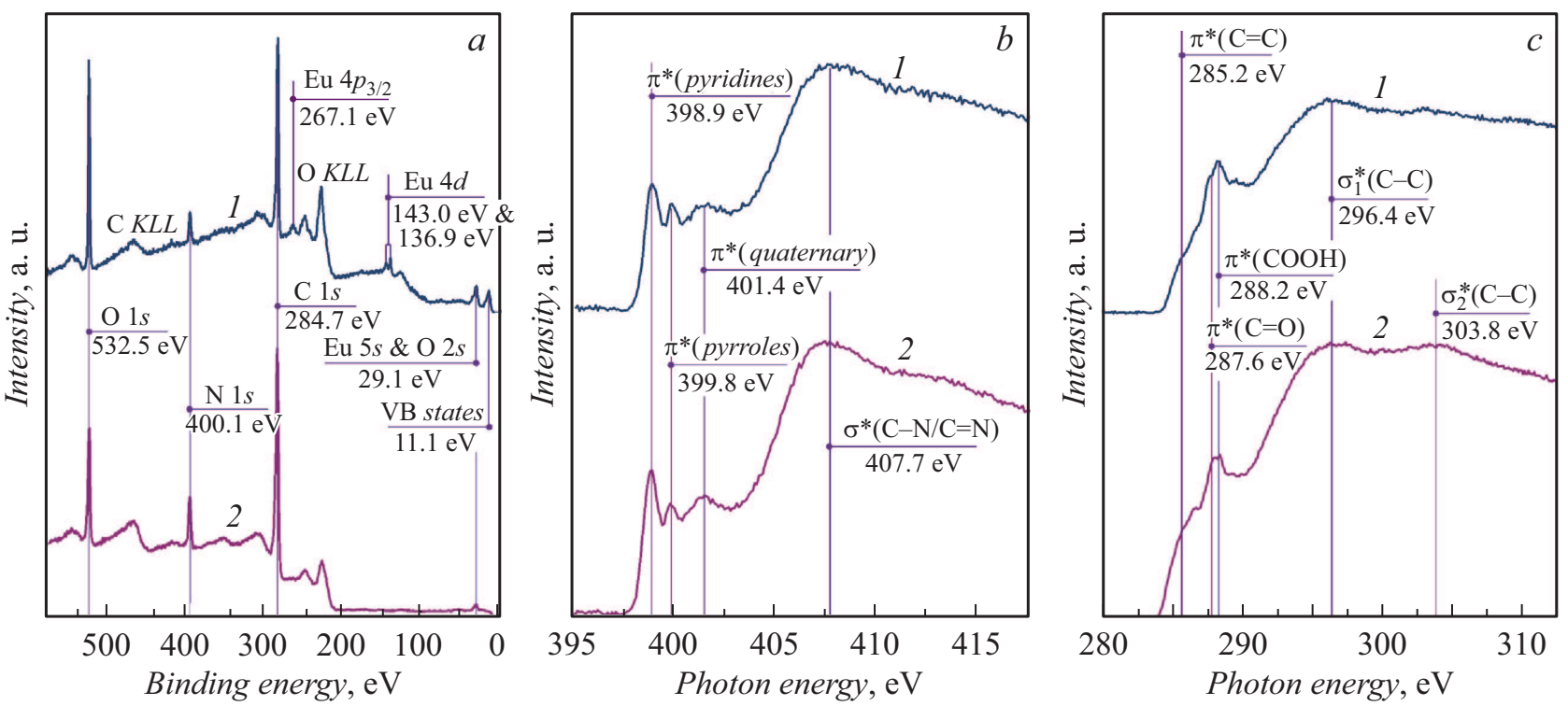

Рис. 3. Обзорный РФЭ-спектр $(a)$, рентгеновский спектр $K$-края поглощения азота $(b)$ и рентгеновский спектр $K$-края поглощения углерода $(c) .1-\mathrm{MCD}: \mathrm{Eu}, 2-\mathrm{MCD}$.

(замещающем азоте) вблизи $401.4 \mathrm{eV}$ и $\sigma^{*}$-резонанс переходов в связях $\mathrm{C}-\mathrm{N} / \mathrm{C}=\mathrm{N}$ во всех состояниях $\mathrm{N}$ вблизи $407.7 \mathrm{eV}$ [20]. Отметим, что, несмотря на снижение концентрации $\mathrm{N}$ в $\mathrm{MCD}: \mathrm{Eu}$, относительное содержание азота в различных состояниях не изменяется по сравнению с MCD, на что указывает сохранение относительной интенсивности всех рассмотренных $\pi^{*}$-резонансов в обоих РП-спектрах.
Более подробная информация о составе кислородсодержащих групп, а также о степени кристаллизации углерода была получена на основе анализа РСП вблизи $K$-края углерода (рис. 3,c). В спектрах как MCD, так и MCD:Eu отсутствует выраженный $\pi^{*}$-резонанс вблизи $285.2 \mathrm{eV}\left(\pi^{*}(\mathrm{C}=\mathrm{C})\right)$, соответствующий переходам остовных C $1 s$-электронов на делокализованные $\pi^{*}$-орбитали и обусловленный наличием в материале 
участков бездефектной графеновой решетки размером более $1-2 \mathrm{~nm}[11,18]$. Поэтому углеродная матрица в обоих образцах представляет собой преимущественно аморфный углерод с малым содержанием субнанометровых участков $s p^{2}$-гибридизованного углерода. При этом в MCD:Eu таких участков меньше, на что указывает снижение интенсивности поглощения в области $\pi^{*}(\mathrm{C}=\mathrm{C})$-резонанса, а также $\sigma_{2}^{*}(\mathrm{C}-\mathrm{C})$-резонанса, соответствующего переходам $\mathrm{C} 1 s$-электронов на локализованные $\sigma^{*}$-орбитали. Это в свою очередь сопровождается ростом относительной концентрации карбоксильных групп $(R-\mathrm{COOH})$ по сравнению с концентрацией карбонилов $(\mathrm{C}=\mathrm{O})$, как видно из перераспределения относительных интенсивностей соответствующих резонансов $\pi^{*}(\mathrm{COOH})$ и $\pi^{*}(\mathrm{C}=\mathrm{O})$ вблизи 288.2 и $287.6 \mathrm{eV}$ [21]. Данные изменения в структуре MCD после модификации $\mathrm{Eu}$ совместно с изменением концентраций N- и Oсодержащих групп указывают на то, что при синтезе $\mathrm{MCD}: \mathrm{Eu}$ катионы или фрагменты кислородсодержащих соединений $\mathrm{Eu}^{3+}$ встраиваются в структуру $\mathrm{MCD}$ в области дефектов углеродной матрицы, образуя химические связи с ее краевыми функциональными группами. Изменение состава самих наноточек и их функциональных групп при модификации европием (рис. 3), повидимому, является причиной наблюдаемой в спектре $\mathrm{MCD}: \mathrm{Eu}$ широкополосной люминесценции (кривая 2 на рис. 1), поскольку увеличение количества кислорода в поверхностных группах приводит к длинноволновому сдвигу ФЛ $[22,23]$.

Таким образом, в работе темплатным методом синтезированы модифицированные европием монодисперсные углеродные наноточки со средним размером $3.5 \mathrm{~nm}$, обладающие яркой фотолюминесценцией в диапазоне $350-850 \mathrm{~nm}$. В качестве темплата использованы монодисперсные сферические частицы мезопористого кремнезема. Методами РФЭС и РСП обнаружено увеличение концентрации кислорода в 2 раза и двукратное снижение концентрации азота в $\mathrm{MCD}: \mathrm{Eu}$ по сравнению с соответствующими значениями для немодифицированных наноточек, что, по-видимому, обусловливает уширение и длинноволновый сдвиг спектра ФЛ. Продемонстрированный подход применим для синтеза $\mathrm{MCD}$, модифицированных различными ионами редкоземельных элементов, а также ионами $d$-элементов. Синтезированный нанолюминофор MCD:Eu имеет перспективы для использования в медицине и оптоэлектронике.

\section{Благодарности}

Работа выполнена с использованием оборудования Федерального центра коллективного пользования „Материаловедение и диагностика в передовых технологиях“ (ФТИ им. А.Ф. Иоффе, Санкт-Петербург).

М.К. Рабчинский благодарит Берлинский центр материалов и энергии им. Гельмгольца и РоссийскоГерманскую лабораторию синхротрона BESSY за предо- ставленную возможность проведения и поддержку РФЭС- и РСП-измерений.

Авторы благодарят Д.А. Смирнова за помощь в проведении РФЭС- и РСП-измерений.

\section{Финансирование работы}

Работа финансировалась за счет средств госбюджета по госзаданию 0040-2019-0012.

\section{Конфликт интересов}

Авторы заявляют, что у них нет конфликта интересов.

\section{Список литературы}

[1] H. Chander, Mater. Sci. Eng. R, 49, 113 (2005). DOI: $10.1016 /$ j.mser.2005.06.001

[2] M. Cesaria, B. Di Bartolo, Nanomaterials, 9, 1048 (2019). DOI: 10.3390/nano9071048

[3] S.N. Baker, G.A. Baker, Angew. Chem. Int. Ed., 49, 6726 (2010). DOI: $10.1002 /$ anie. 200906623

[4] B. Zhao, Z. Tan, Adv. Sci., 8, 2001977 (2021). DOI: $10.1002 /$ advs.202001977

[5] Z. Hallaji, Z. Bagheri, S.O. Kalji, E. Ermis, B. Ranjbar, FlatChem, 29, 100271 (2021). DOI: $10.1016 /$ j.flatc.2021.100271

[6] H.X. Kang, J.X. Zheng, X.G. Liu, Y.Z. Yang, New Carbon Mater., 36, 649 (2021). DOI: $10.1016 / \mathrm{S} 1872-5805(21) 60083-5$

[7] Y. Chen, Y. Liu, M.T. Zheng, H. Zhang, J. Zhuang, B. Lei, Nanoscale, 7, 20142 (2015). DOI: 10.1039/C5NR05637C

[8] D.A. Eurov, D.A. Kurdyukov, A.V. Medvedev, D.A. Kirilenko, M.V. Tomkovich, V.G. Golubev, Nanotechnology, 32, 215604 (2021). DOI: 10.1088/1361-6528/abe66e

[9] E.Yu. Trofimova, D.A. Kurdyukov, S.A. Yakovlev, D.A. Kirilenko, Yu.A. Kukushkina, A.V. Nashchekin, A.A. Sitnikova, M.A. Yagovkina, V.G. Golubev, Nanotechnology, 24, 155601 (2013). DOI: 10.1088/0957-4484/24/15/155601

[10] Д.А. Курдюков, Д.А. Еуров, Е.Ю. Стовпяга, Д.А. Кириленко, С.В. Коняхин, А.В. Швидченко, В.Г. Голубев, ФТТ, $58 \quad$ (12), 2454 (2016). DOI: $10.21883 / \mathrm{ftt} .2016 .12 .43872 .186$ [D.A. Kurdyukov, D.A. Eurov, E.Yu. Stovpiaga, D.A. Kirilenko, S.V. Konyakhin, A.V. Shvidcenko, V.G. Golubev, Phys. Solid State, 58 (12), 2545 (2016). DOI: 10.1134/S1063783416120167].

[11] D.A. Kurdyukov, D.A. Eurov, M.K. Rabchinskii, A.V. Shvidchenko, M.V. Baidakova, D.A. Kirilenko, S.V. Koniakhin, V.V. Shnitov, V.V. Sokolov, P.N. Brunkov, A.T. Dideikin, Y.M. Sgibnev, L.Yu. Mironov, D.A. Smirnov, A.Ya. Vul', V.G. Golubev, Nanoscale, 10, 13223 (2018). DOI: $10.1039 / \mathrm{c} 8 \mathrm{nr} 01900 \mathrm{~b}$

[12] M. Rabchinskii, L. Mironov, Y. Sgibnev, I. Kolesnikov, D.A. Kurdyukov, D.A. Eurov, D.A. Kirilenko, A.V. Shvidchenko, D. Stolyarova, D. Smirnov, V.G. Golubev, Nanotecnology, 30, 475601 (2019).

DOI: $10.1088 / 1361-6528 / \mathrm{ab} 3 \mathrm{cdf}$

[13] D.K. Nelson, B.S. Razbirin, A.N. Starukhin, D.A. Eurov, D.A. Kurdyukov, E.Yu. Stovpiaga, V.G. Golubev, Opt. Mater., 59, 28 (2016). DOI: 10.1016/j.optmat.2016.03.051 
[14] P.B. Hirsh, A. Howie, R.B. Nicholson, D.W. Pashley, M.J. Whelan, Electron microscopy of thin crystals (Butterworths, London, 1965).

[15] S.L. Molodtsov, S.I. Fedoseenko, D.V. Vyalikh, I.E. Iossifov, R. Follath, S.A. Gorovikov, M.M. Brzhezinskaya, Y.S. Dedkov, R. Püttner, J.-S. Schmidt, V.K. Adamchuk, W. Gudat, G. Kaindl, Appl. Phys. A, 94, 501 (2009). DOI: $10.1007 / \mathrm{s} 00339-008-4916-1$

[16] J. Ryu, E. Lee, K. Lee, J. Jang, J. Mater. Chem. B, 3, 4865 (2015). DOI: 10.1039/C5TB00585J

[17] X. Yu, H. Hantsche, Fresen. J. Anal. Chem., 346, 233 (1993). DOI: $10.1007 / \mathrm{BF} 00321421$

[18] B.J. Schultz, R.V. Dennis, J.P. Aldinger, C. Jaye, X. Wang, D.A. Fischer, A.N. Cartwright, S. Banerjee, RSC Adv., 4, 634 (2014). DOI: 10.1039/C3RA45591B

[19] M.K. Rabchinskii, S.A. Ryzhkov, M.V. Gudkov, M.V. Baidakova, S.D. Saveliev, S.I. Pavlov, V.V. Shnitov, D.A. Kirilenko, D.Yu. Stolyarova, A.M. Lebedev, R.G. Chumakov, M. Brzhezinskaya, K.A. Shiyanova, S.V. Pavlov, V.A. Kislenko, S.A. Kislenko, A. Makarova, V.P. Melnikov, P.N. Brunkov, 2D Materials, 7, 045001 (2020). DOI: 10.1088/2053-1583/ab9695

[20] A. Sliwak, B. Grzyb, N. Diez, G. Gryglewicz, Appl. Surf. Sci., 399, 265 (2017). DOI: 0.1016/j.apsusc.2016.12.060

[21] M.K. Rabchinskii, A.S. Varezhnikov, V.V. Sysoev, M.A. Solomatin, S.A. Ryzhkov, M.V. Baidakova, D.Yu. Stolyarova, V.V. Shnitov, S.S. Pavlov, D.A. Kirilenko, A.V. Shvidchenko, E.Yu. Lobanova, M.V. Gudkov, D.A. Smirnov, V.A. Kislenko, S.V. Pavlov, S.A. Kislenko, N.S. Struchkov, I.I. Bobrinetskiy, A.V. Emelianov, P. Liang, Z. Liu, P.N. Brunkov, Carbon, 172, 236 (2021). DOI: $10.1016 /$ j.carbon.2020.09.087

[22] C.M. Carbonaro, R. Corpino, M. Salis, F. Mocci, S.V. Thakkar, C. Olla, P.C. Ricci, J. Carbon Res., 5, 60 (2019). DOI: $10.3390 / \mathrm{c} 5040060$

[23] H. Ding, X.H. Li, X.B. Chen, J.S. Wei, X.B. Li, H.M. Xiong, J. Appl. Phys., 127, 231101 (2020). DOI: 10.1063/1.5143819 